\title{
Pedagogy in a Pandemic: Teaching without Exams
}

\author{
James Andrew Smith \\ Electrical Engineering and Computer Science Department, Lassonde School of Engineering \\ York University \\ Toronto, Canada \\ drsmith@yorku.ca
}

\begin{abstract}
Due to the pandemic lockdown, York University's Fall 2020 offerings of a pair of 1st and 2nd year undergraduate engineering and computer science courses were heavily modified to accommodate a completely online approach to teaching. The objective was to maximize interactivity and hands-on elements while also providing a supportive and authentic learning experience. Class presentations were made asynchronous by uploading them to YouTube and superimposing H5P elements via our Moodle-based LMS. Our traditional laboratory equipment was replaced with inexpensive lab kits that were obtained from commercial vendors and shipped to students via the university's Bookstore. All tests, quizzes and exams were eliminated in both courses. Instead, a specifications-based assessment approach was taken, with all students given the opportunity to achieve a $B+$ if they completed all the work in the class. Students who wished to submit a final project could do so for an opportunity to boost their grade to A or A+. Most intra-semester deadlines were removed, with material associated with the synchronous lab sessions being the notable exception. The resulting grade distribution and averages were similar to previous years in which we relied to in-person testing. The rate of $\mathrm{A} / \mathrm{A}+$ was $21 \%$ and $8 \%$, while the failure rate was $13 \%$ and $3 \%$, respectively, for the first and second year classes. Informal feedback from students, including those with academic accommodations, was nearly universally positive, with most acknowledging that their stress levels were lower, making the learning more manageable.
\end{abstract}

En raison de la crise sanitaire et le confinement COVID19, deux cours d'ingénierie de 1ère et 2ème année de l'université York ont été modifiés pour s'adapter à une approche d'enseignement entièrement numérique. L'objectif des adaptations était de permettre aux étudiants d'apprendre du matériel technique de manière pratique et interactive sur internet. Les présentations en classe ont été rendues interactives et asynchrones en les téléchargeant sur YouTube et en superposant des ressources H5P via notre environnement numérique d'apprentissage Moodle. Nos équipements de laboratoire traditionnel ont été remplacé par des kits de laboratoire abordables obtenus auprès de fournisseurs commerciaux et expédiés aux étudiants via la librairie de l'université. Nous avons éliminé tous les tests, questionnaires et examens dans les deux cours. Une approche basée sur les spécifications a été adoptée, permettant les élèves d'obtenir un B+ s'ils terminent tous les travaux de la classe. Les étudiants qui souhaitaient un $A$ ou A+ devaient soumettre un projet final. La plupart des délais intra-semestriels ont été supprimés, le matériel associé aux sessions de laboratoire synchrones étant l'exception notable. La distribution des notes et les moyennes étaient similaires aux années au cours desquelles nous nous sommes appuyés sur des tests en personne. Le taux de A / A + était de $21 \%$ et $8 \%$, tandis que le taux d'échec était

An earlier version of this manuscript appeared as a personal blog post de $13 \%$ et $3 \%$, respectivement, pour les classes de premières et deuxièmes années. La rétroaction informelle des étudiants, y compris ceux qui avaient des accommodements scolaires, était presque universellement positive, la plupart reconnaissant que leur niveau de stress était réduit et que l'apprentissage était gérable.

Index Terms-COVID, pandemic, H5P, online teaching, specifications-based learning, proficiency-based teaching, programming, Arduino, Matlab, Java.

\section{INTRODUCTION}

The COVID19 pandemic has shaken up the world of education. While the negative impact on teaching and learning is generally clear, for those of us who have been advocating for progressive changes to post-secondary education it has also provided us with an opportunity to engage in that change. This paper is a description of attempts to make changes that address both (1) the immediate needs of our students during the pandemic and (2) long-term changes that can be implemented in the post-pandemic educational landscape.

\section{A. Online Exam Integrity is a Myth}

The need to maintain the integrity of an assessment system, whether it is in the form of an exam or not, is vital in the contemporary educational system. This need justifies the resources that faculty and staff pour into traditional examinations in postsecondary institutions. For instance, in a pre-pandemic context York University's EECS Department has had an excellent "Lab Test Mode" for in-person lab-based programming assessments that prevents unauthorized communications with lab-based desktop computers all the while permitting students to use local and online resources for computer programming tests. [1].

I acknowledge that assessment integrity is important. However, it is practically impossible to maintain traditional exam integrity while teaching online. There are two reasons for this: technology and perception. Hardware and software technologies such as search engines, forums, chat channels, web-facilitated contract cheating [2], network-connected telephones, watches, tablets, "smart speakers" and full-fledged computers are omnipresent. They are difficult to block during non-pandemic in-person exams and impossible while students are remote. There are two perceptual reasons that exacerbate this issue. First, these technologies are too familiar, easy to use 
[3] and generally too useful for students to put away. Second, the risk tradeoff of getting caught is perceived by students to favour their use during exams.

Case in point: The winter 2020 version of YorkU's EECS 1011 class was taught by a colleague. The course had approximately 70 students enrolled in the course. As of the time of this writing, I am overseeing academic misconduct charges that have been laid against approximately $25 \%$ of these students, stemming from an online final exam in April 2020. When interviewed about these charges, many of the students immediately admitted to the use of online tools and collaboration with their classmates. While upset about being caught, it appears that the use of Discord during the final exam was a natural extension of the students' online learning practices.

\section{B. Understand \& Leverage Student Motivations While Online}

In this paper, I argue that educators need to acknowledge the COVID-driven online education "elephant in the classroom": that success in online education requires redesigning and recreating teaching material [4] such that we may "stimulate student motivation and interest in learning instead of in cheating." [5] To succeed, educators need to fully embrace the technological and perceptual realities of teaching online, to understand that while we teach online, traditional examinations are effectively obsolete. The use of proctoring software and methods to prop up these obsolescent assessment modes should be avoided as they are violations of students' rights to privacy and are detrimental to the goal of leveraging student motivations [6] to provide an authentic learning experience. Furthermore, the asymmetric nature of the technologies and motivations are firmly on the side of the students, just as they were on the side of illegal music downloaders in the BitTorrent and Napster days. Today's educators should design their online classes to incentivize honest and authentic learning in the same way that the music industry embraced seamless online commercial music platforms [7] to defeat illegal music downloading.

\section{Specifications-BASED GRAding}

The typical assessment model in the Western tradition is, especially in the summative cases, a posteriori - particular assessment questions and weights are unknown prior to the assessment. In contrast, the specifications-based approach aims to be more predictable (a prior). [8]-[10] In specs-grading, students know ahead-of-time how much any assessment or subcomponent of an assessment will be worth within a particular grouping of deliverables and, by extension, to their final grade. The allows them to allocate time and resources relative to predicted effort and reward. For many, specsgrading is especially compelling because it reflects how work is undertaken in many employment settings that students will encounter outside of the classroom setting.

In these two courses the specs-based grading process changes the assessment model from one of relatively arbitrary, tiny point-based grades slices (e.g. a final exam is worth $35 \%$ of the final grade and each question on the exam is worth a certain fraction of that that is unknown to the student ahead of time) to one in which students strive towards the completion of weighted "bins" or "bundles" of work. [8]-[10]

Unlike the two-level rubric system (pass/fail or satisfactory/unsatisfactory) typical of specs-grading, [8] we continued to use Lassonde School's already established four-level rubric system, illustrated in Fig. 1. This four-point rubric system has been in use in the Lassonde School since 2015. It maps to the Canadian Engineering Accreditation Board's twelve graduate attributes. Within the Lassonde School we have established a list of approximately 70 "graduate attribute indicators" (GAIs) that break down the CEAB's characteristics such that they be applied to a wide variety of courses. Each GAI has four descriptors, permitting them to be applied in rubrics such as those shown here in Figs. 2 and 3.

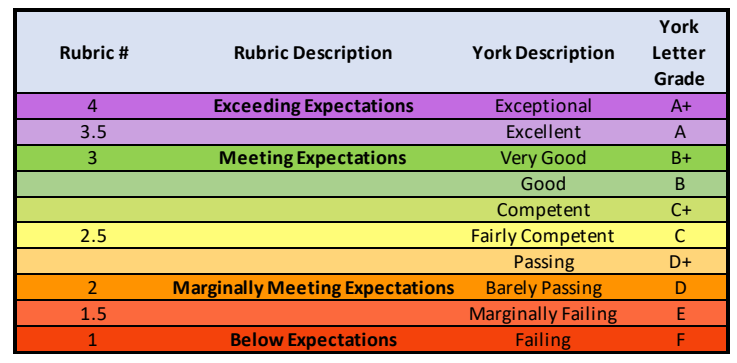

Fig. 1. The four-level rubric descriptors used at YorkU's Lassonde School, with mappings to a four-point numeric grade scale and to YorkU's current university-wide letter grade breakdown and descriptors.

\section{A. No Exams! Just do the Work to get a B+}

The specifications-based grading was explained to EECS 1011 and 2021 students as follows:

If you complete all the work in the course you'll get a $B+$. No midterm, no final exam. To achieve an A or A+ you will need to perform additional work related to a major programming project.

To achieve the B+ in EECS 1011 the students needed to finish four "bundles" of work, each worth $20 \%$ of the final grade. These bundles were

1) Labs (lab reports, lab demonstrations, etc.): $20 \%$

2) Class Readings and videos (tracked on the LMS): $20 \%$

3) Online interactive activities (Matlab Grader, non-video H5P, etc.): $20 \%$

4) Minor Project: $20 \%$

Each subcomponent within a bundle was worth one point: each lab report or demo was worth one point in the lab bundle, each interactive video completed was worth one point in the interactive bundle, etc. Each point in a bundle category was valued as an equal fraction of the $20 \%$ weighting of the bundle.

The EECS 2021 course worked similarly, but there was no minor project, just a major project. In that case, the three required components were worth $26.7 \%$ of the final grade (for $80 \%$ total), while the major project took up the final $20 \%$.

In each course, the optional "major project" component worth $20 \%$ was available to all students. Completing the major 
project made it possible for students to obtain an $\mathrm{A}$ or $\mathrm{A}+$ in either course. In both courses the major project was thematically more open-ended that the EECS 1011 minor project. This open-endedness is similar to the approach typically taken in engineering capstone courses and in the introductory Biomedical Engineering course I had taught previously. [11] The rubric for the EECS 2021 major project is shown in Fig. 3. The rubric for the EECS 1011 major project was similar to that of the minor project. The students submitted both written and video reports of their projects.

The breakdown of the bundles in this was was a deliberate decision to ensure that the course would not become a vehicle for an "easy A." Effectively, a B or B+ was considered to be "meeting expectations" vis-à-vis learning outcomes of the course. This was an important criterion to avoid delegitimizing this initiative.

Synchronous class sessions over Zoom were held during the regularly scheduled class times, were completely optional and were not graded. Recordings of these sessions were made available to students and not tied to any part of the assessment scheme. Asynchronous recordings of class material were uploaded to YouTube (https://bit.ly/38hOnON and https://bit.ly/3rp09yF) and then imported to our LMS via the H5P "interactive video" plugin scheme. [12] The interactive activities consisted of questions (multiple choice, true-false, fill-in-the-blanks, etc.) and were graded as part of one of the grading bundles. An example is shown in Fig. 4.

In both courses any interactive online components (driven by the H5P and Matlab Grader plugins on Moodle) could be repeated until the student demonstrated proficiency. [12], [13] The vast majority of interactive online activities were due by the end of the semester. The only exceptions were those that were directly tied to the weekly lab activities. Lab demonstrations were conducted synchronously over Zoom under supervision by lab teaching assistants and technical staff. These lab demonstrations and any lab reports could only be done or handed in once and had fixed deadlines. This was due, in large part to the limitations imposed by teaching assistant resource allocations.

\section{Assessment AS A DESIGN PROBlem}

I'm trained as an engineer and often think of problems in terms of design and performance. If the operating conditions for which an object was designed change beyond specified tolerances, then the object may fail. Recently, power generation units in Texas (both renewable and non-renewable) failed due to a drop in temperature in the southern United States. In more northern jurisdictions power generation units continued as normal because the designs for those units made them resistant to the colder weather. [14] Power generation failed in Texas because power operators made incorrect design decisions related to operating conditions. Likewise, when we try to shoehorn an in-person class to online delivery we shouldn't be surprised if the experience fails for both student and instructor.

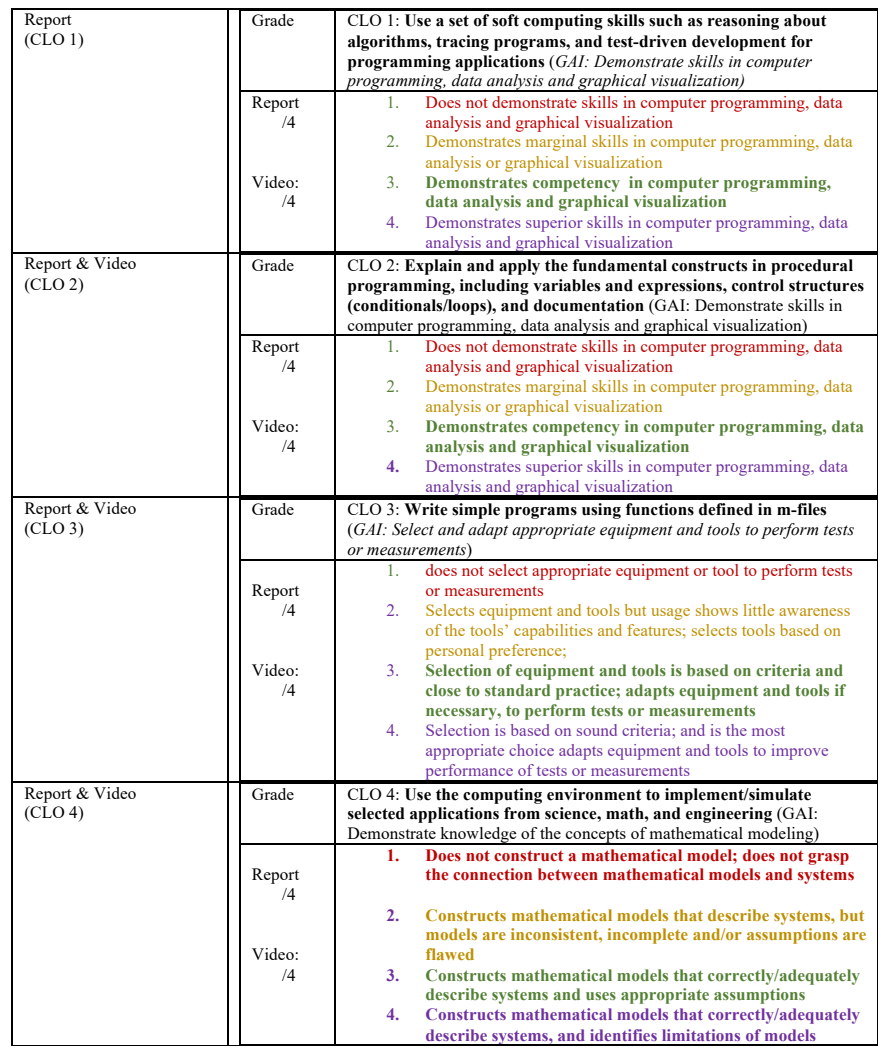

Fig. 2. The four-level rubric system applied to the EECS 1011 minor project. It was provided to the students in terms of both course-specific learning outcomes (CLOs) and program-wide "Graduate Attribute Indicators" (GAIs).

We should reflect on teaching and learning as design problems. What are the specifications for learning? What are the conditions under which that learning is to occur? What is optimal learning? What instruments do we use to measure it and how do set up testing frameworks and workflows? Just like in a traditional engineering design we need to verify that our proposed teaching assessment designs meet requirements and can be used as intended.

Even outside the context of online learning for engineering or computer science education, it's clear that traditional, proctored, in-person summative exams may not be the most appropriate tool for assessing learning. We see that [15] suggests

- Traditional cumulative exams are neither the only nor the best way to assess achievement in engineering courses;

- It is possible to implement alternative strategies, such as offering a higher frequency of less weighted tests; and

- it is important to be creative and think beyond written tests.

For instance, prior to the pandemic my colleagues and I at YorkU had found flipped classes and two-stage exams [16] were effective alternatives for learning and assessment of learning.

As we made the sudden transition to online teaching during the Fall 2020 lockdown, many university instructors transi- 


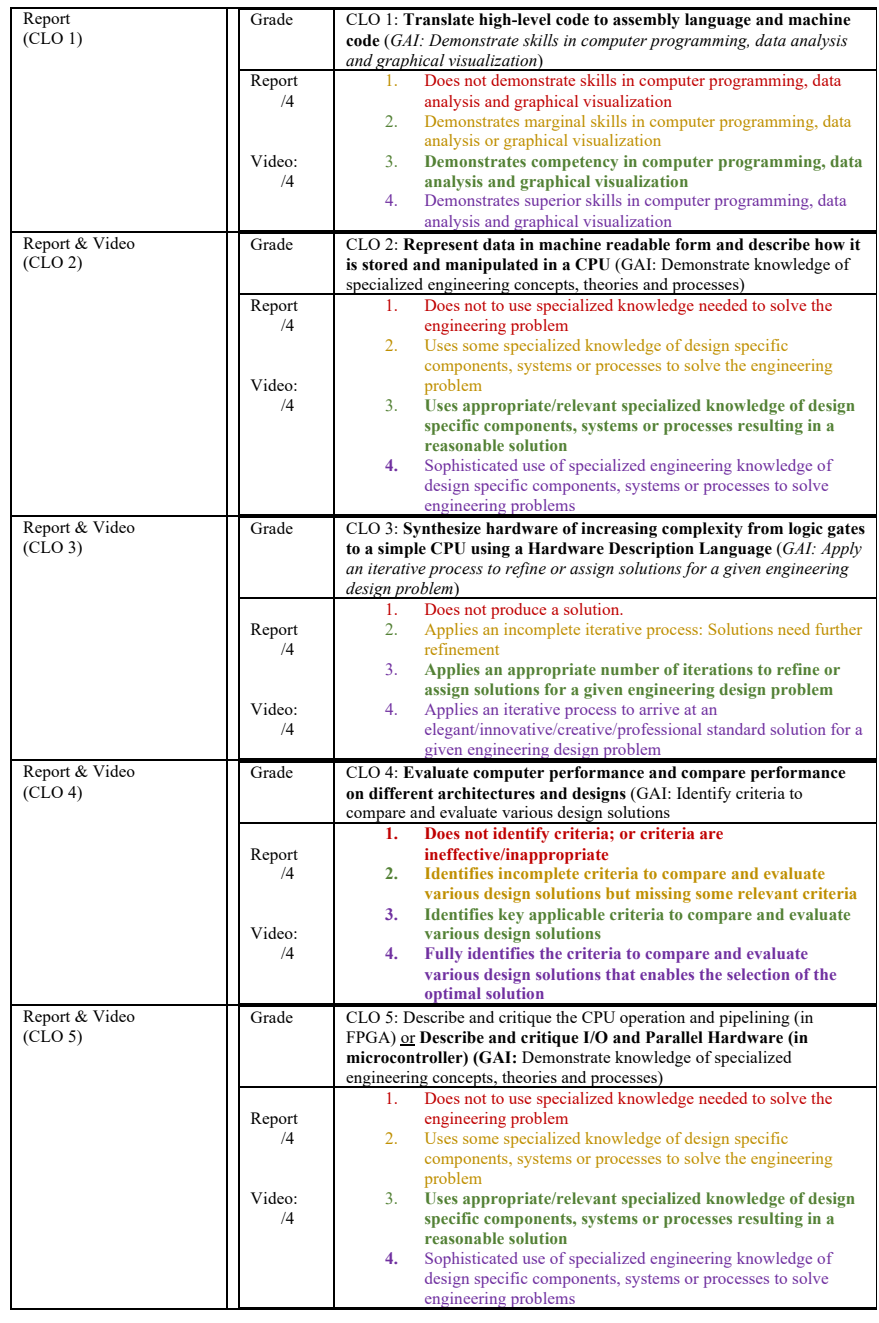

Fig. 3. The four-level rubric system applied to the EECS 2021 major project. It was provided to the students in terms of both course-specific learning outcomes (CLOs) and program-wide "Graduate Attribute Indicators" (GAIs).

tioned the traditional, in-person, proctored summative exam model to the online environment, assuming that the assessment design could withstand the new operating conditions with the help of modified proctoring methods, including the infamous ProctorTrack. [17], [18]

\section{A. Just Say No to ProctorTrack}

Many of my colleagues - and, likely, many of yours insisted that online summative exams had to continue in the online environment during the pandemic, no matter the evidence that cheating was rampant and proctoring software was ineffective.

Here, I advocate for faculty to reduce or, better yet, eliminate altogether the use of remote proctoring techniques as they are not as effective as one might think and open up moral issues related to invasion of student privacy. These proctoring techniques span from locking students up in a washroom with an active webcam [19, minute 58 of linked podcast] to the use of facial-tracking in commercial software like ProctorTrack [20] and the adaptation of platforms like Zoom to traditional exam systems ("so that your face and hands can be seen during the exam") as has been done at Germany's TUM [21], [22].

Since the Spring of 2020 I've witnessed a number of internal discussions at YorkU about what to do about online teaching and assessment. I imagine that these are similar to those outside of YorkU. Much of the discussion has, in my mind, been wasted on tweaking and tuning remote proctoring for online testing. While initially there was much technical [23] and faculty support for technology like ProctorTrack, enthusiasm for it began waning over the Summer of 2020 as reports came back that it was terribly invasive and did not appear to be effective. By February 2021, the York University Senate suggested that ProctorTrack no longer be used. [24]. The Senate's position follows on the heels of our engineering and computer science school-wide recommendation to do away with ProctorTrack. Our Dean's Office communicated the following in the Fall of 2020:

- A pilot student was conducted with ProctorTrack and the outcome was negative

- Insufficient research has been conducted as to its effectiveness in eliminating cheating

- Forcing students to turn on their cameras contradicts our institution's messaging on respecting students' right to privacy

- Internet connectivity cannot be guaranteed during an exam

As such, online proctoring systems such as ProctorTrack are losing momentum as solutions. In parallel, instructors are discovering for themselves that the online exam process does not favour academic integrity, is difficult to administer and runs counter to our mandate for accessibility and fairness. [25] The theme of online exams discussion, by the end of the Fall 2020 semester, appears to have shifted from "we have to lock down exams" to "oh, yeah, students cheated on final exams because they have access to Discord, WhatsApp, Chegg, etc. and we can't do anything about it."

This has reinforced perspective from earlier in the COVID lockdown that that many professors have been barking up the wrong assessment tree. Generally speaking, in-person exams make sense, but online exams do not. We just simply should not be putting much effort or faith into exams right now. That said, proposals like the one in this paper are viewed with scepticism. The initial results for specs-based assessments as described here are, in my mind, promising but many of my colleagues are doubtful. A longer term tracking of student learning outcomes is needed and I hope to compare student results during in-person teaching in 2021 through 2023 to see if students who took alternative pathways will do better or worse in terms of demonstrating proficiencies in learning outcomes.

\section{DyNAMIC LEARNING ONLINE FROM Home}

While many faculty transitioned to online learning by simply recording lectures and posting them online or students to participate in synchronous lecture sessions on Zoom or equiv- 
alent, I didn't think that that would be particularly effective for my engineering or computer science students.

Instead, I spent the Spring and Summer of 2020 working with colleagues to ensure that we had lab kits and interactive learning modules on our Learning Managment System (LMS), Moodle.

\section{A. Labs from the Kitchen Table}

During the lockdown in the Spring of 2020, I leveraged a prepandemic grant focused on inexpensive Arduino-based lab kits from the Lassonde School's Dean's Office to create a lab kit centred on an offering from Seeed Studio for the EECS 1011 students (Grove Beginner Kit for Arduino) and an offering from Microchip Technology for the EECS 2021 students (ATmega328P Xplained Mini), both based on the Arduinofriendly ATMEGA328 microcontroller. Stock for both was plentiful (1000+ units) and could be obtained directly from the manufacturers or from a variety of resellers. The Arduino platform was particularly useful as inexpensive alternatives and clones are available worldwide. It was important that the lab kits be available for both students in the Greater Toronto Area, but also for students in Iran, Sri Lanka, Pakistan, Nigeria, Chile, the PRC and elsewhere - some of which had important trade embargoes in place. ${ }^{1}$

The Seeed Studio-based lab kit is shown in Fig. 6. The York University Bookstore bundled useful components such as water pumps and a multimeter and provided students with low-cost replacement parts from a dedicated webpage, https: //bit.ly/3bmlGCf.

The EECS 1011 minor project combined the basic lab kit with a live, student-supplied plant. Students were encouraged to either use any house plant that they already owned, an offthe-shelf plant or one grown from seed. The use of a plant with the lab kit was a deliberate one as we wanted to have students work with something natural, in contrast to the artificial nature of the other elements in the course.

\section{B. Interactive Learning Lectures}

Dozens of low-stakes interactive activities were developed for delivery on Moodle for both EECS 1011 and EECS 2021. They relied on the H5P plugins for Moodle and included multiple-choice questions, word searches, 4 group sharing, drag-the-words, and interactive videos. 4 Video content was hosted on YouTube and interactive questions overlaid using H5P.

All of the "lecture" content was pre-recorded using Camtasia, posted on YouTube and imported into our Moodle system (dubbed "eClass" at York), with interactive questions superimposed. That meant that all of the key learning content could be viewed over-and-over, both on Moodle and on a lowestcommon-denominator video platform outside of Moodle. It allowed for active learning, with a contemporary look-andfeel.

\footnotetext{
${ }^{1}$ Options for students who could not access YorkU Bookstore products was important: https://drsmith.blog.yorku.ca/2020/10/ lab-kit-for-eecs-1011-and-1021/
}

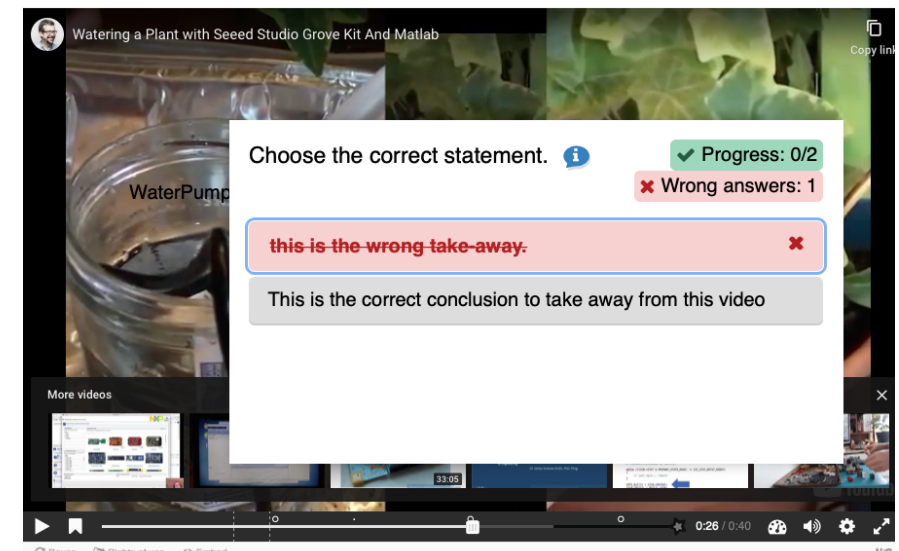

Fig. 4. Example interactive video combining YouTube content with H5P questions on Moodle (eClass)

\section{Word search for PIC32 (MIPS) assembler mnemonics, bit operations}

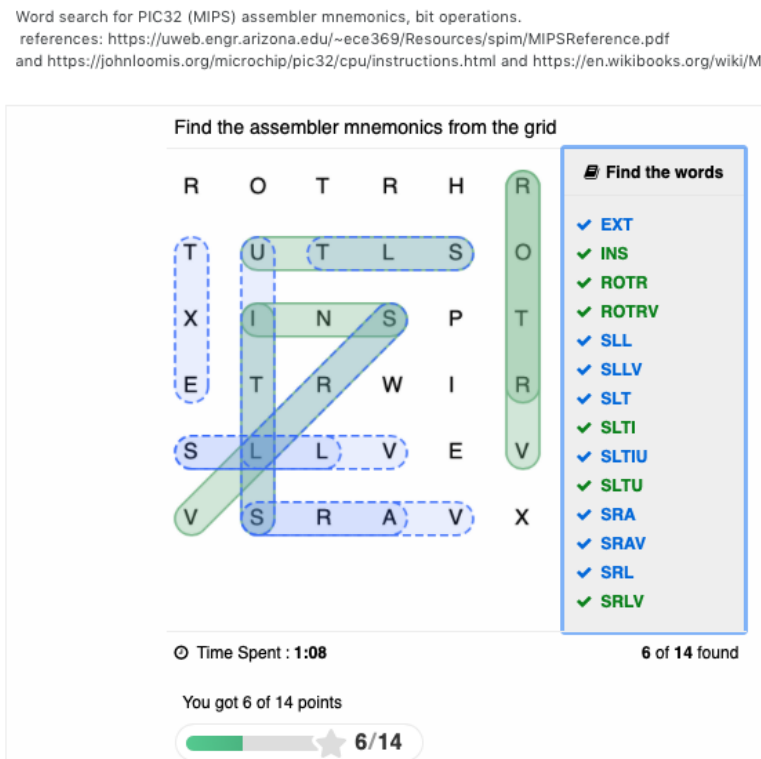

Fig. 5. Example H5P word search activity on Moodle (eClass)

All of the scheduled class times were made into optional synchronous sessions on Zoom. They effectively became public office hours for the students to ask me (and themselves) questions. I also still held all of my office hours on Zoom, but keep those sessions one-on-one.

1) Interactive Programming Problems: While our department has long had an online programming assessment system, it is dated, relatively difficult to use. Compared to current systems on platforms such as JetBrains' Academy (Hyperskill), the existing system is functional but its interface is dated, nor particularly flexible and does not integrate with other LMS-based tools. For teaching during the pandemic we switched to Matlab Grader for EECS 1011 as it integrated well with both the LMS and the course material. [26] We also 


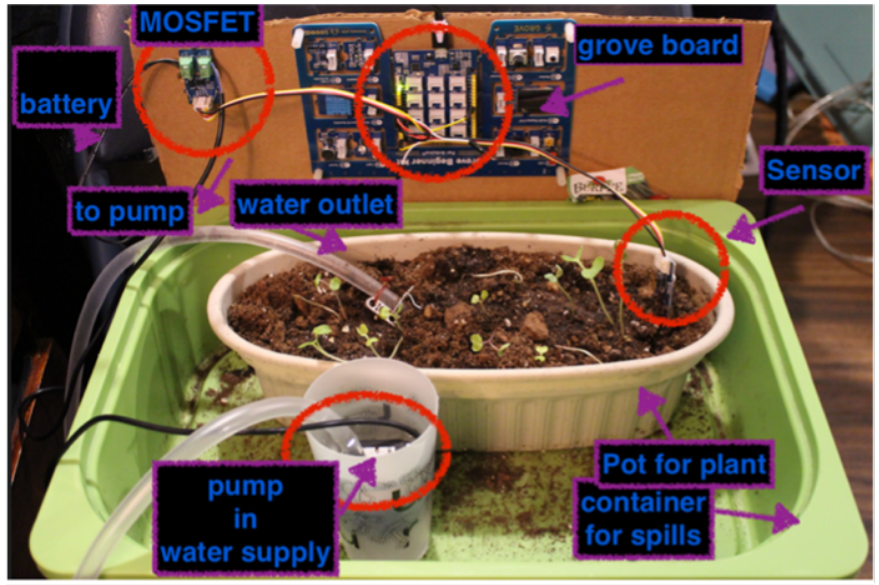

Fig. 6. The EECS 1011 Lab Kit, based on the Seeed Studio Grove Beginner Kit for Arduino, connected to a house plant for use in the minor project.

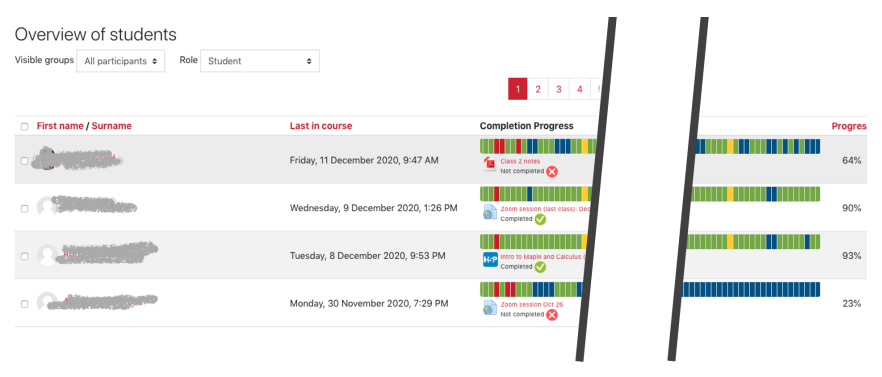

Fig. 7. An example of the completion tracker view for EECS 1011.

introduced Virtual Programming Lab (VPL) plugin for Moodle for courses that had non-Matlab programming elements like C, Java, Python, Assembler, etc. [27] In the Winter 2021 semester, VPL was used in EECS 1021, the sequel to EECS 1011 as the course is based on Java. VPL may be used in the future for EECS 2021 as a vehicle for Verilog exercises, but was not used in the Fall of 2020.

2) Completion Tracking: A completion tracker was engaged within the Moodle-based LMS, eClass for both courses, as shown in Fig. 7. Completion trackers have widely been seen to be important tools in helping students succeed while doing online learning.

The completion tracker helped students determine what work they had to do throughout the semester. It also permitted the teacher to identify and reach out to students who are falling behind, prompting student responses such as:

Thank you for your interest and for checking up with me. This is the first time a professor actually reaches out to check and remind me to complete work and i really appreciate it .

\section{RESUlts}

Here we will examine the final grade results and feedback from students. Generally, the results have been favourable.
EECS 1011 Grade Distribution

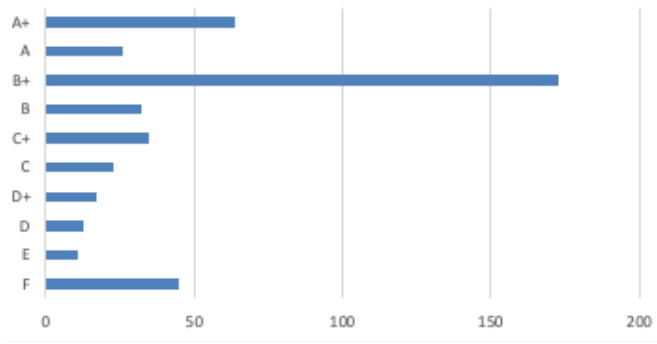

Fig. 8. Grade Distributions in EECS 1011 (Fall 2020).

\section{A. Grading}

1) EECS 1011 Grades and Completion Rates: In EECS 1011 the average for the class was $68.4 \%$, with a high standard deviation of $20.4 \%$. The average was about the same as in previous editions of the course, but the standard deviation was higher. The distribution of the final grades in the Fall 2020 semester was: $21 \% \mathrm{~A}$ or $\mathrm{A}+, 39 \% \mathrm{~B}+, 7 \% \mathrm{~B}, 8 \% \mathrm{C}+, 5 \% \mathrm{C}$, $7 \% \mathrm{D}$ or $\mathrm{D}+$, and $13 \% \mathrm{E}$ or $\mathrm{F}$.

How did this compare with previous offerings of the EECS 1011? On average, from 2016 to 2020, in EECS1011: 26\% A or $\mathrm{A}+; 37 \% \mathrm{~B}$ or $\mathrm{B}+; 5 \% \mathrm{E}$ or $\mathrm{F}$. So the number of $\mathrm{A}$ or $\mathrm{A}+$ students during the Fall 2020 semester dropped slightly (21\% vs $26 \%$ previously) and the failure rate increased somewhat (13\% vs $5 \%$ previously were $\mathrm{E}$ or $\mathrm{F}$ ). The moderate grades in the Fall 2020 semester skewed heavily towards B or B+ : $46 \%$ of the class received either a B or B+. That was much higher than normal, but was expected due to the nature of the grading scheme. As for the work completion rate, based on the completion tracker for the course:

- \# of students who completed $90 \%$ or more of the activities in the course: $292(66.4 \%)$

- \# of students who completed $75 \%$ to $89.9 \%$ of the activities in the course: $82(18.6 \%)$

- \# of students who completed between $50 \%$ and $74.9 \%$ of the activities in the course: $51(11.6 \%)$

- \# of students who completed under $50 \%$ of the activities in the course: 15 (3.4\%)

- Major Project submissions: 28\% (126/440).

These results stand in contrast to another first year introductory programming class offered in a different program within our department in which over $90 \%$ of the students received an A or A+. That course used the traditional final exam model for assessment, modified for online proctoring in Fall 2020.

2) EECS 2021 Grades and Completion Rates: The average grade for my EECS 2021 class was $73.7 \%$ with a standard deviation of $11.2 \%$. The final grade distribution was: $8 \% \mathrm{~A}$ or $\mathrm{A}+, 53 \% \mathrm{~B}+, 20 \% \mathrm{~B}, 9 \% \mathrm{C}+, 3 \% \mathrm{C}, 4 \% \mathrm{D}$ or $\mathrm{D}+$, and $3 \%$ E or F.

How did this compare with previous offerings of the EECS 2021? On average, from 2016-2020, we saw: $20 \%$ A or A+; $26 \%$ B or B+; $12 \%$ E or F. So in the Fall 2020 semester, for EECS 2021, the number of A or A+ students dropped (8\% 


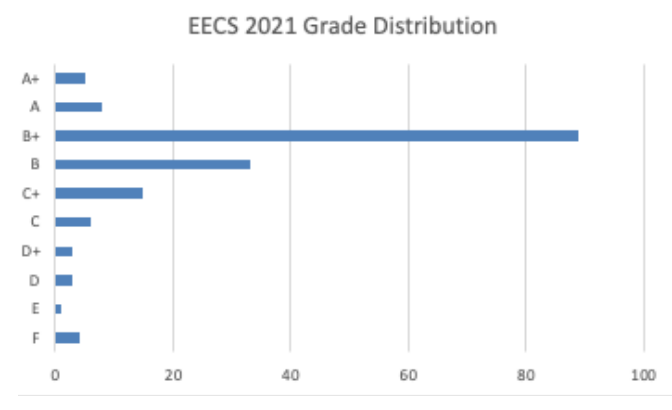

Fig. 9. Grade distributions in EECS 2021 (Fall 2020)

vs $20 \%$ previously), as so did the failure rate (3\% vs $12 \%$ previously were $\mathrm{E}$ or $\mathrm{F}$ ). The moderate grades this semester skewed heavily towards B or B+, as it did with EECS 1011. From the completion tracker on the LMS we saw the

- \# of students who completed $90 \%$ or more of the activities in the course: $140(84 \%)$

- \# of students who completed $75 \%$ to $89.9 \%$ of the activities in the course: 15 (9\%)

- \# of students who completed between $50 \%$ and $74.9 \%$ of the activities in the course: $9(5 \%)$

- \# of students who completed under $50 \%$ of the activities in the course: $3(2 \%)$

- \# of Major Project submissions: 8\% (13/167).

So, in this second year class a strong majority students appeared to have aimed for and obtained the $\mathrm{B}+$ (or B), more so than in the first year course, EECS 1011, where relatively fewer students were able to achieve that standard.

Interestingly, a second section of EECS 2021 was taught in parallel by another faculty member and adhered to more traditional model of assessment while online The average in that section was approximately $20 \%$ less than in the specificationsbased approach.

In the case of these two courses, the "no easy A" design criteria was met. The number of students that attempted the major project (the only route to an $\mathrm{A}$ or $\mathrm{A}+$ ) was no more than a third of the class (28\% in EECS 1011 and $8 \%$ in EECS 2021). A clear majority of the students in both classes did not attempt to boost their grade, but the vast majority (66\% in EECS 1011 and $80 \%$ in EECS 2021) finished over $90 \%$ of the learning tasks in the course.

\section{B. Student Feedback}

The following are typical remarks made by students in the Fall 2020 end-of-semester satisfaction surveys:

- I really enjoyed that all the lectures were asynchronous, so I was able to work through them on my own time. The content was clearly explained with good powerpoints [sic] and physical demonstrations where needed, and the use of HP5 activities for evaluation was favorable [sic].

- Lectures and videos can be done at own pace

- How understanding the prof was. Some profs are disrespectful and don't consider the current situation we are all in.
- The fact that there are no midterm tests or final exams but I happened to learn more from this course than others. The videos that we have to watch and answer questions in between are very effective in retaining information.

When asked if they would change anything about either course, many students replied with variants of:

- Absolutely nothing

That said, some students would have preferred to see more structure in the optional synchronous classes:

- Although I found the weekly interactive videos very useful and informative, currently the class time was more of a $Q \& A$ session. The $Q \& A$ time was very useful, but maybe dedicating the first half of the class to be a review of the videos and the second half to be a $Q \& A$ could be more effective.

Interestingly, many students still wanted to have final exams:

- Give the option to also do a final exam/test for the $20 \%$

This leads me to consider plans for teaching in a postpandemic university environment.

\section{Looking Ahead to Post-Pandemic Teaching}

It is clear to me that the updates to the courses while online have been a success. Students were engaged and they appreciated the flexible, asynchronous nature of many components in these courses. For commuter schools like UBC or York University, providing flexibility for students to learn from an off-campus location is desirable. ${ }^{2}$

While many students found the lack of exams a valuable aspect of the courses, an important portion of them would prefer examination-based assessment. Clearly both students and faculty value them and should be considered for reintroduction when we go back to face-to-face teaching, but perhaps in modified form or weight. In particular, I'm likely to reintroduce two-stage examinations [16] as I have found these to be particularly effective in the past, both at YorkU and while teaching in Germany. ${ }^{3}$

\section{CONCLUSIONS}

The removal of exams and the introduction of specificationsbased grading, asynchronous class material, interactive online activities and inexpensive take-home lab kits in the Fall 2020 offering of EECS 1011 and EECS 2021 were very positive. The average grades in the two Fall 2020 courses were similar to what they were pre-pandemic and are not characterized by anomalous results with respect to excessively high grades. When we eventually go back to face-to-face teaching I will keep asynchronous and interactive online content delivery, as well as the take-home lab equipment, for the same reasons being put forward in the context of other commuter schools [28]. While in-person testing is still important and should be re-introduced post-pandemic, the alternative approaches to teaching and assessment piloted during the 2020/21 academic

\footnotetext{
${ }^{2}$ UBC: https://bit.ly/3eoDsad, YorkU: https://bit.ly/3rsKcr0

${ }^{3}$ Two stage exams in Germany: https://drsmith.blog.yorku.ca/2018/09/ embeddedcourse karlsruhe/
} 
year have shown that in-person testing does not need to be the main vehicle for assessment.

\section{ACKNOWLEDGMENTS}

First, much of my inspiration and guidance in teaching including the material discussed here - comes from the continuous conversations I have with my professionally-trained educator wife, Ms. Michelle Huth. Second, the work behind much of what is described here was inspired by the "Taking it Online!" course with Dr. Robin Sutherland-Harris and YorkU's Teaching Commons. My classmates from that course and I have since met on a nearly weekly basis to discuss the successes, failures and "astuces". This group includes Dr. Meg Luxton (LAPS School of Gender, Sexuality and Women's Studies), Dr. Sabine Dreher (Glendon Campus, International Studies Dept), Dr. Josée Rivest (Glendon Campus, Centre for Cognitive Health), and Dr. Shirley Roburn (LAPS, Dept. of Communication Studies). I also need to thank Mr. Patrick Thibeaudeau and Ms. Lisa Caines Ogini at YorkU's University IT Deparment, Mr. Muhammad Javeed in the Lassonde School, our fantastic tech team in the EECS department comprised of Ms. Ulya Yigit, Mr. Jason Keltz, Mr. Paul Griffith, Mr. Jaspal Singh, Ms. Seela Balkissoon, Mr. Nam Tran, Mr. Gayan Gamage, Mr. Eric Prandovszky, and others. The changes to computing hardware and software on campus, their willingness to get onboard with all my crazy ideas and to counter them with practical ideas of their own you're all fantastic! Thanks to Prof. Iris Epstein, and Prof. Melanie Baljko and the other members of the SMART Toolbox project for giving some helpful structure to the student video submissions. Thank you to Dr. Jeff Harris for pointing me to Dr. Talbert's blog posts on specifications-grading. Thank you to Ms. Laura Deszpa and her team at the YorkU Bookstore for helping put together our lab kits and getting them out to students. I also need to shout out to Ms. Nada Savicevic and Ms. Nadia Desai from the Chang School at Ryerson for working with me so many years ago on a course and the paper.

\section{REFERENCES}

[1] EECS Department Staff, "Labtest mode." Online, March 2021. https: //wiki.eecs.yorku.ca/dept/tdb/services:labtest:start.

[2] T. Lancaster and C. Cotarlan, "Contract cheating by stem students through a file sharing website: a covid-19 pandemic perspective," International Journal for Educational Integrity, vol. 17, no. 1, pp. 1-16, 2021.

[3] A. Chirumamilla, G. Sindre, and A. Nguyen-Duc, "Cheating in e-exams and paper exams: the perceptions of engineering students and teachers in norway," Assessment \& Evaluation in Higher Education, vol. 45, no. 7, pp. 940-957, 2020

[4] D. J. Evans, B. H. Bay, T. D. Wilson, C. F. Smith, N. Lachman, and W. Pawlina, "Going virtual to support anatomy education: A stopgap in the midst of the Covid-19 pandemic in the midst of the covid-19 pandemic," Anatomical Sciences Education, vol. 13, no. 3, pp. 279-283, 2020.

[5] O. R. Harmon, J. Lambrinos, and J. Buffolino, "Assessment design and cheating risk in online instruction," Online Journal of Distance Learning Administration, vol. 13, no. 3, 2010.

[6] T. S. Plowman, "Academic integrity and informational technology," TechTrends, vol. 44, no. 1, p. 24, 2000.

[7] J. Waldfogel, "Music file sharing and sales displacement in the itunes era," Information economics and policy, vol. 22, no. 4, pp. 306-314, 2010.
[8] R. Talbert, "Specifications grading: We may have a winner." Online, April 28 2017. https://web.archive.org/web/*/https://rtalbert.org/ specs-grading-iteration-winner/.

[9] M. Levine, "Advocating a new way of grading," University Times (University of Pittsburg), May 15 2014. https://web.archive.org/web/ 20201029061645/https://www.utimes.pitt.edu/archives/?p=30598.

[10] P. Leslie and E. Lundblom, "Specifications grading: What it is, and lessons learned," Seminars in Speech and Language, vol. 41, no. 04 pp. 298-309, 2020.

[11] J. A. Smith, "A project-oriented bme survey course: Making pass-fail grading work," in Proceedings of the BMES 2010 Annual Meeting, (Austin, Texas, USA), October 2010.

[12] P. Sinnayah, A. Salcedo, and S. Rekhari, "Reimagining physiology education with interactive content developed in h5p," Advances in Physiology Education, vol. 45, no. 1, pp. 71-76, 2021.

[13] C. Demazière, "Using active learning in hybrid learning environments," in EPJ Web of Conferences, vol. 247, p. 14001, EDP Sciences, 2021.

[14] S. Carpenter, "Why wind turbines in cold climates don't freeze: De-icing and carbon fiber," Forbes, Feburary 2021. https://bit.ly/3gV0XZs.

[15] A. Haghnegahdar, "Alternatives to heavily-weighted final exams in engineering courses," Teaching Innovation Projects, vol. 3, no. 1, 2013.

[16] T. Kelly, "Two-stage tests: turning testing into learning opportunities across course assessments," Ontario Consortium of Undergraduate Biology Educators, 2016.

[17] M. Chin, "Exam anxiety: How remote test-proctoring is creeping students out," The Verge, April 292020.

[18] J. Binstein, "On knuckle scanners and cheating - how to bypass proctortrack, examity, and the rest." Online, January 2015 https://web.archive.org/web/20180628021241/https://jakebinstein.com/ blog/on-knuckle-scanners-and-cheating-how-to-bypass-proctortrack/.

[19] G. KJ6VU Zafiropoulos and J. KF7IJZ Kolonay, "Remote ham radio license exams and remote field day (ham radio workbench)." Online, March 2020. https://web.archive.org/web/ 20200807174540/https://www.hamradioworkbench.com/podcast/ remote-ham-radio-license-exams-and-remote-field-day.

[20] J. Lee, R. J. Kim, S.-Y. Park, and M. A. Henning, "Using technologies to prevent cheating in remote assessments during the covid-19 pandemic," Journal of dental education, 2020.

[21] Staff, "Digitale pruefungsleistungen mittels TUMExam (digital exam submission with TUMExam)," tech. rep., Technical University of Munich Department of Informatics, January 2021.

[22] T. U. M. LSR-ITR Department, "Online exams (lsr-itr startseite)." Online, January 2021. https://web.archive.org/web/20210208094037/https: //wiki.tum.de/display/lsritr/Online+Exams.

[23] UIT Staff / BOLD (York University), "Using proctortrack for remote exam proctoring." Online, August 2020. https://web.archive.org/web/ 20200918204929/https://bold.info.yorku.ca/remoteproctoring/.

[24] A. MacPherson, "COVID-19 pandemic and academic continuity; restricting use of online proctoring of examinations," report, Senate, York University, Toronto, ON, Canada, February 2021.

[25] S. Asgari, J. Trajkovic, M. Rahmani, W. Zhang, R. C. Lo, and A. Sciortino, "An observational study of engineering online education during the covid-19 pandemic," Plos one, vol. 16, no. 4, p. e0250041, 2021.

[26] S. Song, M. Antonelli, T. W. Fung, B. D. Armstrong, A. Chong, A. Lo, and B. E. Shi, "Developing and assessing matlab exercises for active concept learning," IEEE Transactions on Education, vol. 62, no. 1, pp. $2-10,2018$.

[27] D. Thiebaut, "Moodle vpl tutorials." Online, April 2018. https://web.archive.org/web/20210224200215/http://www.science. smith.edu/dftwiki/index.php/Moodle_VPL_Tutorials.

[28] J. A. Smith, "Twitter live-post of gacip summit plus 2020." Online, December 102020 . https://twitter.com/jasmith_yorku/status/ 1337115183169363971 . 